\title{
Modeling Math Growth Trajectory-An Application of Conventional Growth Curve Model and Growth Mixture Model to ECLS K-5 Data
}

\author{
Yi Lu (Corresponding author) \\ American Institute for Research \\ 1000 Thomas Jefferson Street NW, Washington DC 20007, USA
}

Tel: 1-202-403-6541_E-mail: yi.lu0519@gmail.com

Received: March 22, 2016 Accepted: April 29, 2016 Published: May 2, 2016

doi:10.5296/jei.v2i1.9197ＵRL: http://dx.doi.org/10.5296/jei.v2i1.9197

\begin{abstract}
To model students' math growth trajectory, three conventional growth curve models and three growth mixture models are applied to the Early Childhood Longitudinal Study Kindergarten-Fifth grade (ECLS K-5) dataset in this study. The results of conventional growth curve model show gender differences on math IRT scores. When holding socio-economic status (SES) constant, gender differences reduced on the mean start IRT scores, growth rate, and acceleration rate. Growth mixture modeling applied to ECLS K-5 children reliably identified three classes of children based on their math growth trajectories. Growth mixture modeling results indicate that gender differences are different depending on different math development classes. After controlling for SES, growth mixture modeling results show that gender differences on the mean start IRT scores, linear growth rate, and quadratic growth rate reduced in all subpopulations. Growth mixture modeling result also show that after controlling for gender, the effects of SES on math development are different in different subpopulations.
\end{abstract}

Keywords: Math growth trajectory, Conventional growth curve model, Growth mixture model, ECLS K-5 dataset

\section{Introduction}

Sponsored by the National Center for Education Statistics, Early Childhood Longitudinal Study Kindergarten-Fifth grade (ECLS K-5) is designed to document the educational status and progress of a nationally representative sample of children from kindergarten through fifth grade (U.S. Department of Education, 2000). For the base year, a nationally representative 
sample of 21,260 children attending kindergarten in the Fall of 1998 was drawn through the use of a multistage probability sample design. The primary sampling units were geographic areas consisting of counties or groups of counties from which 1,280 public and private schools offering kindergarten programs were selected. A target sample of approximately 24 children from each public school and 12 children from each private school was drawn, with Asian/Pacific Islander students oversampled. Each sampled child was linked to his or her kindergarten teacher (Tourangeau, Nord, Lê, Pollack, \& Atkins-Burnett, 2006).

Applying this dataset, there are many studies focused on factors that influence reading achievement or reading trajectory from kindergarten to first grade (e.g., Dawson \& Williams, 2008; Duncan \& Magnuson, 2005; Han, 2008; Hong \& Raudenbush, 2005; Kaplan, 2002, 2005; McCoach, O'Connell, \& Levitt, 2006; Xue \& Meisels, 2004). The other content area, mathematics, as one way to understand the world around us, not only sets a solid foundation for later academic study but also prepares students as citizens of the technological society. The current study focuses on math growth using ECLSK-5 dataset.

The statistical techniques most often applied to address development questions are either variable-centered or person centered (Connell \& Frye, 2006; Jung \& Wickrama, 2008). Variable-centered approaches such as regression, factor analysis, and structural equation modeling focus on describing the relationship among variables. This approach may obscure the real variability in scores across individuals and groups of individuals within a sample since it employs the average variable scores across a sample. Conventional growth curve model is primarily variable-centered in that it based on the assumption that the studied sample is from a single population with the same average start value and same average growth rate (Kaplan, 2002). Nevertheless, conventional growth curve model has been routinely applied to educational data to examine developmental trajectories. Person-centered perspective, on the other hand, relaxes the heroic assumption of single population and addresses information about interindividual differences in intraindividual change over time (Nesselroade, 1991). Growth mixture model is a person-centered approach to model students' academic achievement over time as it assumes that each smaller population has its own unique trajectory. As one of the recent developments in statistical techniques for handling longitudinal data from a person-centered perspective, growth mixture modeling technique offers a robust mean of identifying subgroups of populations following distinct growth trajectories, by which the unobserved heterogeneity of individual difference in growth over time can be captured.

\section{Perspective and Research Questions}

The mathematics assessment items in the ECLS k-5 data were designed to measure skills in conceptual knowledge, procedural knowledge, and problem solving. Considering the critical importance of mathematics, both conventional growth curve modeling and growth mixture modeling are conducted in this study to investigate students' math growth trend in the elementary years. To investigate students' general level and rate of math growth, conventional growth curve model without predictors is initiated first. The general theory of students' math achievement growth is curvelinear during the elementary school years (e.g., Raudenbush, 
2001; Singer \& Willet, 2003). In line with this general theory of growth, a quadratic slope is also included in the initial conventional growth curve model. The gender difference in math performance is a concern in many studies (e.g. Hyde, Fennema, \& Lamon, 1990; Lindberg, Hyde, Petersen, \& Linn, 2010; Penner \& Paret, 2008; Thompson \& Dinnel, 2007). In order to investigate whether there are any significant gender differences on math growth among the ECLS K-5 students, gender as a variable is added to the first model to form the second conventional growth curve model. Socio-economic status (SES) is one of the most widely used contextual variables in educational research. There are substantial studies focusing on the effect of SES on students' academic achievement (e.g., Bradley \& Corwyn, 2002; Duncan \& Magnuson, 2005; Sirin, 2005), therefore, in the third conventional growth curve model, in addition to gender, SES is also added as time-varying predictor. To test whether there exists more than one population, the above three models are then performed in the framework of growth mixture model. The specific research questions for the growth mixture models are: (1) Are there unique classes of children defined by their growth curves in math? (2) How do the growth rates for children within these classes differ between boys and girls? (3) After controlling for SES, how do the growth rates differ between boys and girls within each class?

\section{Data Source}

The released public use ECLS K-5 includes 6 rounds of data collection: Fall and Spring kindergarten, Fall and Spring first, Spring third, Spring fifth. To conduct the conventional growth curve model and growth mixture model, five measurement points were chosen in this study: Spring kindergarten, Fall first, Spring first, Spring third, and Spring fifth. The initial measurement point, Fall kindergarten, provides convenience to understand the initial status of children's math. Nevertheless, initial measurement point only provides little information about the growth rate at the onset of the study, this measurement points is not included in the current study. Among all the participants, 2818 students who were measured at those five waves are selected in this study. As to the missing data, generally, there are three types of missing data: missing completely at random, missing at random, and missing not at random. In the ECLS K-5 data, it is reasonable to assume data missing at random. In the current study, missing data is handled by maximum likelihood method, and software program Mplus is used to get estimation (L. K. Muthén \& B. O. Muthén, 2001).

\section{Methods}

\subsection{Conventional Growth Curve Modeling}

Conventional growth curve modeling is a procedure that has been advocated for the study of intraindividual differences in change. Conventional growth curve modeling can provide an estimate of the average initial and average growth rate of the interested population. From the structural equation modeling perspective, conventional growth curve modeling is specified in two parts: (1) measurement part that links repeated measures of an outcome to latent growth factors (2) a structural part that links latent growth factors to each other and to individual-level predictors (Kaplan, 2002). If we define the outcome variable as a $p-$ dimensional vector $\mathbf{y}$, following Muthén (2002) and Kaplan (2002), the measurement part of the model can be expressed as 


$$
\mathbf{y}_{i}=\mathbf{v}+\Lambda \eta_{i}+\mathbf{K} \mathbf{x}_{i}+\mathbf{e}_{i}
$$

Where, the $p$ - dimensional vector $\mathbf{y}_{i}$ representing the empirical growth for child $i$; $\mathbf{v}$ is a $p-$ dimensional parameter vector of measurement intercept; $\Lambda$ is a $p \times m$ matrix of factor loadings; $\eta$ is a $p$-dimensional parameter vector of latent variables; $\mathrm{K}$ is a $p \times q$ parameter matrix of regression slopes; $\mathbf{x}$ is a $q$-dimensional vector of covariates; and $\mathbf{e}$ is a $p-$ dimensional vector of residuals.

The structural part of the model is defined in terms of the latent variables regressed on each other and the $q$-dimensional vector $\mathbf{x}$ of independent variables,

$$
\eta_{i}=\mathbf{a}+\mathbf{B} \eta_{i}+\Gamma \mathbf{x}_{i}+\xi_{i}
$$

Where, $\eta$ is defined as before; $\mathbf{a}$ is a $m$ - dimensional vector that contains the population initial status and growth parameters $\mu_{\pi 0}$ and $\mu_{\pi 1}$; $\mathbf{B}$ is an $m \times m$ matrix containing regression slopes that relate the latent variables to each other; $\Gamma$ is an $m \times q$ matrix of regression coefficients relating the latent growth factors to the independent variables; and $\xi$ is an $m-$ dimensional vector of residuals.

\subsection{Growth Mixture Modeling}

Under the assumption that there exists a finite mixture of populations each with their unique growth trajectories, growth mixture modeling combines conventional growth curve modeling with latent class analysis (Clogg, 1995). For example, in the ECLS K-5 data, it is possible that children sampled from a population exhibiting very different class of math growth: some children may have very rapid rates of growth in math that level off quickly, others may show relatively normal rates of growth, and still others may show slower rate of growth. If this is so, then growth mixture modeling can capture each unique trajectory.

The specification of the growth mixture model is similar to that of the conventional growth curve model. The difference lies in allowing different growth trajectories for different classes (Kaplan, 2002). To reflect the presence of trajectory classes, Equations (1) and (2) can be rewritten as,

$$
\begin{aligned}
& \mathbf{y}_{i}=\mathbf{v}+\Lambda \eta_{i}+\mathbf{K} \mathbf{x}_{i}+\mathbf{e}_{i} \\
& \eta_{i}=\mathbf{a}_{c}+\mathbf{B}_{c} \eta_{i}+\Gamma_{c} \mathbf{x}_{i}+\xi_{i}
\end{aligned}
$$

Where, the subscript $c$ represents trajectory class $(c=1,2, \ldots, C)$. For growth mixture modeling, maximum likelihood with robust standard errors and a mean and variance adjusted chi-square was used as the method of estimation (L. K. Muthén \& B. O. Muthén, 2001).

\section{Results}

Table 1 presents the selected results for the three conventional growth curve models. Model 1 presents the estimate of the growth curve model without predictors. A path diagram of this model is shown in Figure 1. The initial status was set at Spring Kindergarten. The results in Table 1 indicate that the average math IRT scores at Fall Kindergarten is 33.405 IRT points, with a significant and positive growth rate of 12.578 IRT point per semester and a significant 
deceleration rate of 0.442 IRT point per semester. Students' mean math achievement vary significantly around the starting point with significant variation in rate of change on math achievement over time and significant variation in deceleration over time.

Table 1. Selected results for three conventional growth curve models

\begin{tabular}{|c|c|c|c|}
\hline Coefficient & Model 1 & Model 2 & Model 3 \\
\hline Mean (int) & 33.405 & 34.064 & 33.816 \\
\hline Mean (slope) & 12.578 & 13.048 & 13.113 \\
\hline Mean (quad) & -0.442 & -0.471 & -0.474 \\
\hline Var (int) & 131.693 & 131.218 & 105.017 \\
\hline Var (slope) & 10.618 & 10.423 & 9.851 \\
\hline $\operatorname{Var}$ (quad) & 0.062 & 0.060 & 0.064 \\
\hline r (int with slope) & 0.459 & 0.456 & 0.332 \\
\hline r(int with quad) & -0.465 & -0.465 & -0.367 \\
\hline r(slope with quad) & -0.898 & -0.899 & -0.896 \\
\hline int on gender & & -1.294 & -1.034 \\
\hline slope on gender & & -0.919 & -0.709 \\
\hline quad on gender & & 0.056 & 0.040 \\
\hline Math1 on SES1 & & & 4.500 \\
\hline Math2 on SES2 & & & 4.027 \\
\hline Math4 on SES4 & & & 5.467 \\
\hline Math5 on SES5 & & & 8.076 \\
\hline Math6 on SES6 & & & 8.131 \\
\hline & $\mathrm{BIC}=107141.4$ & $\mathrm{BIC}=107119.8$ & $\mathrm{BIC}=92497.7$ \\
\hline
\end{tabular}

Note. boys $=0$, girls $=1$; All numbers are significant.

Students who start with high mean math achievement have significantly fast linear growth $\left(r_{(\text {int }, \text { slope })}=0.459\right)$ and significant deceleration $\left(r_{(\text {int }, \text { quad })}=-0.465\right)$. Students who have faster growth of math achievement have significantly faster deceleration $\left.\left(r_{(\text {slope }, \text { quad }}\right)=-0.898\right)$. 


\section{Macrothink}

Results of model 2 in Table 1 provides estimates for conventional growth curve model with gender as a time-invariant predictor of initial status, growth rate, and quadratic term. A path diagram of this model is shown in Figure 2. The regression of initial status on gender shows that girls have a significantly lower initial mean math IRT scores, and a significantly slower linear growth rate and but a significantly faster acceleration rate. Figure 3 presents the estimated average growth trajectories for boys and girls based on conventional growth curve model.

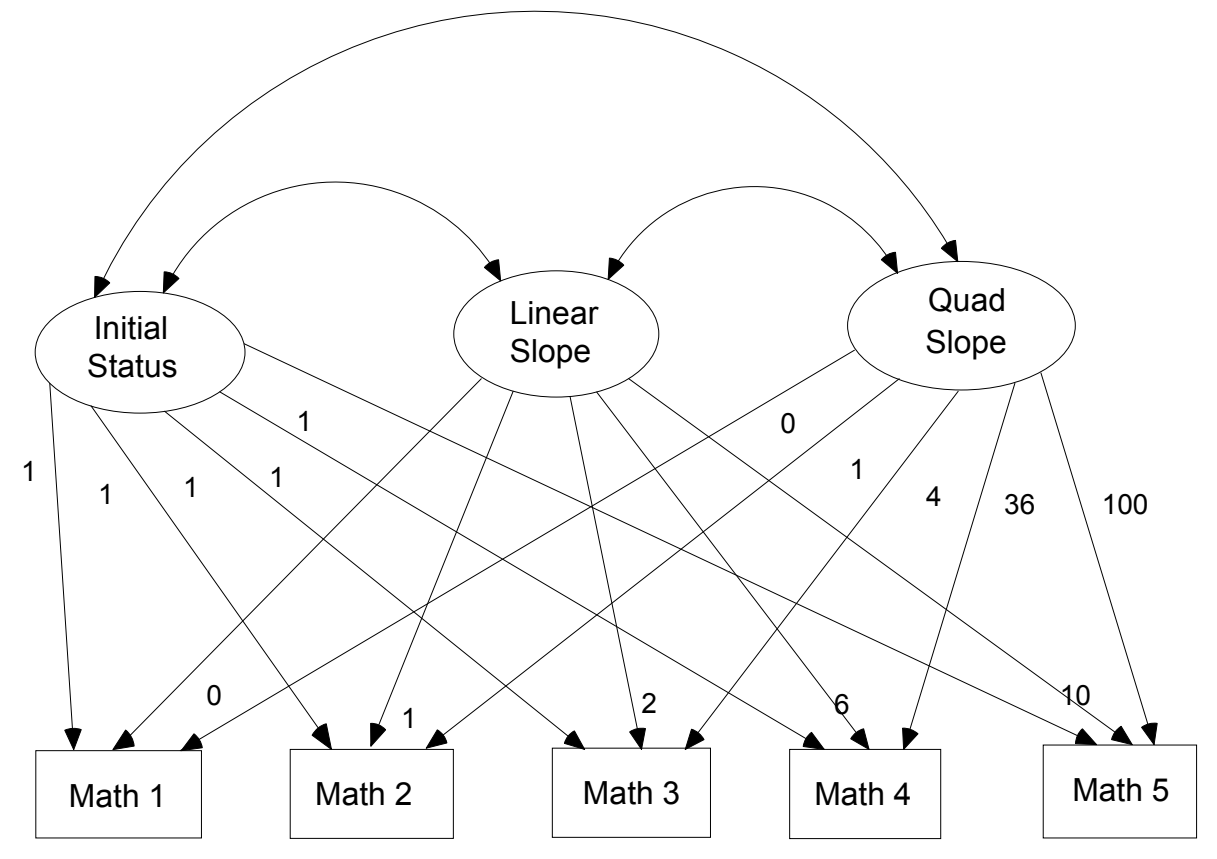

Figure 1. Initial conventional growth curve model of math achievement 


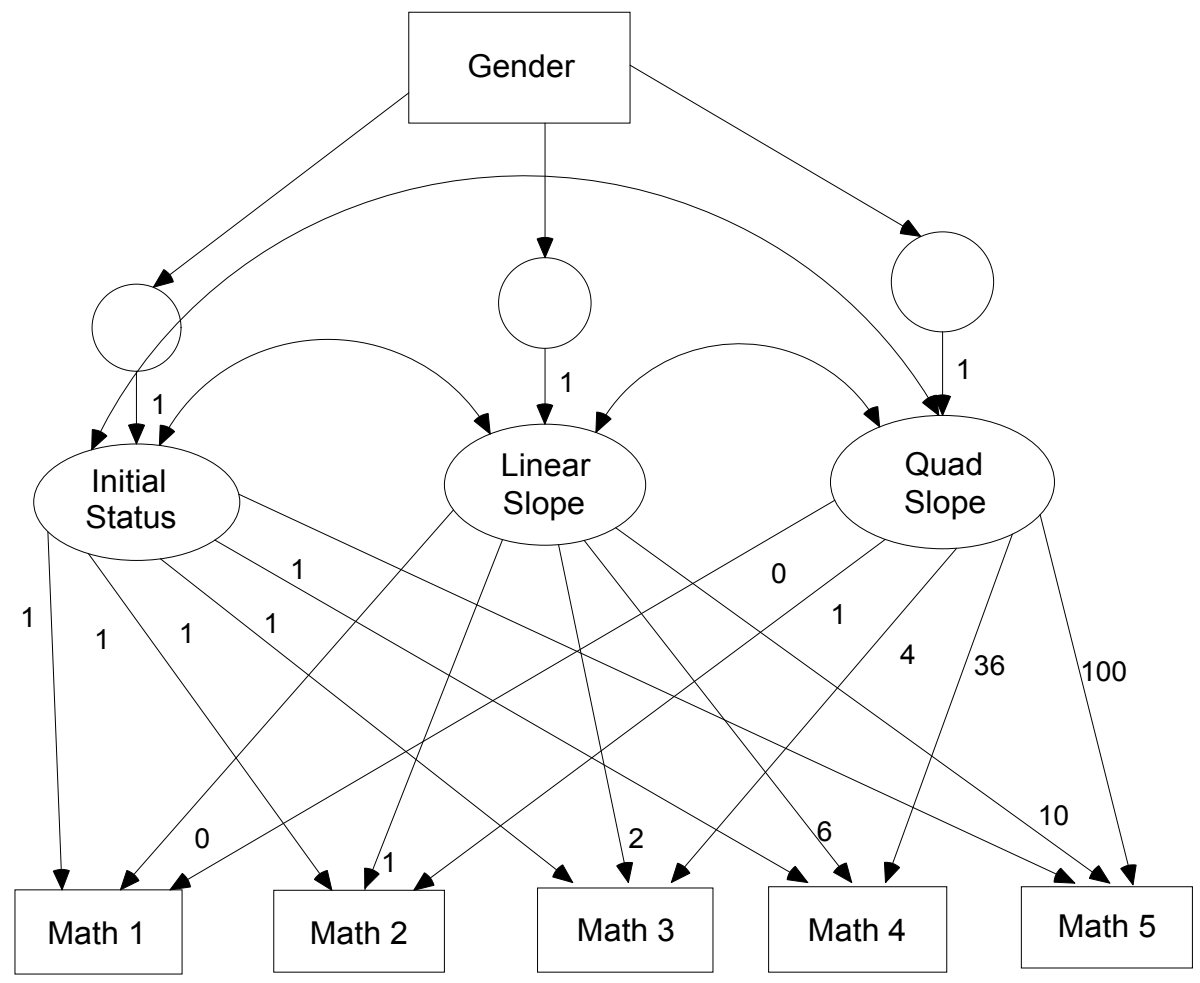

Figure 2. Conventional growth curve model of math achievement with time-invariant predictors

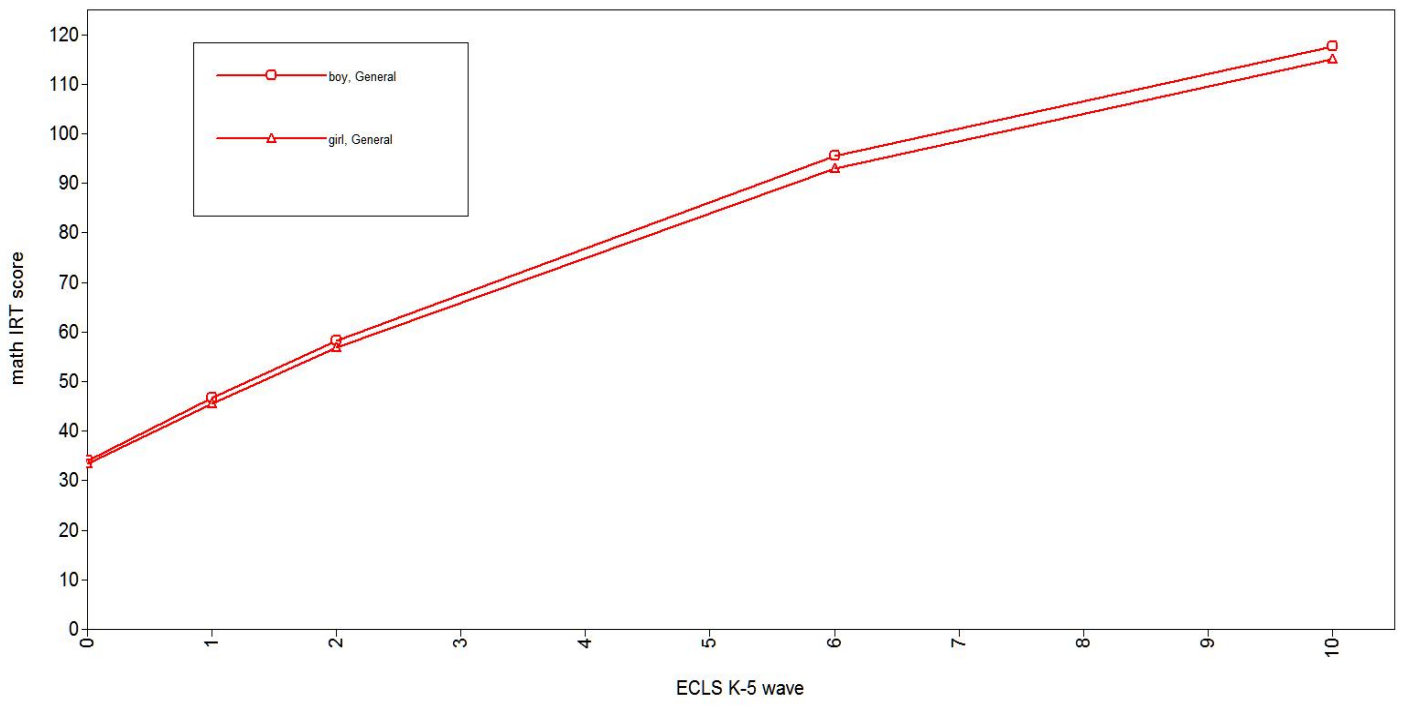

Figure 3. Estimated math growth trajectories for boys versus girls 


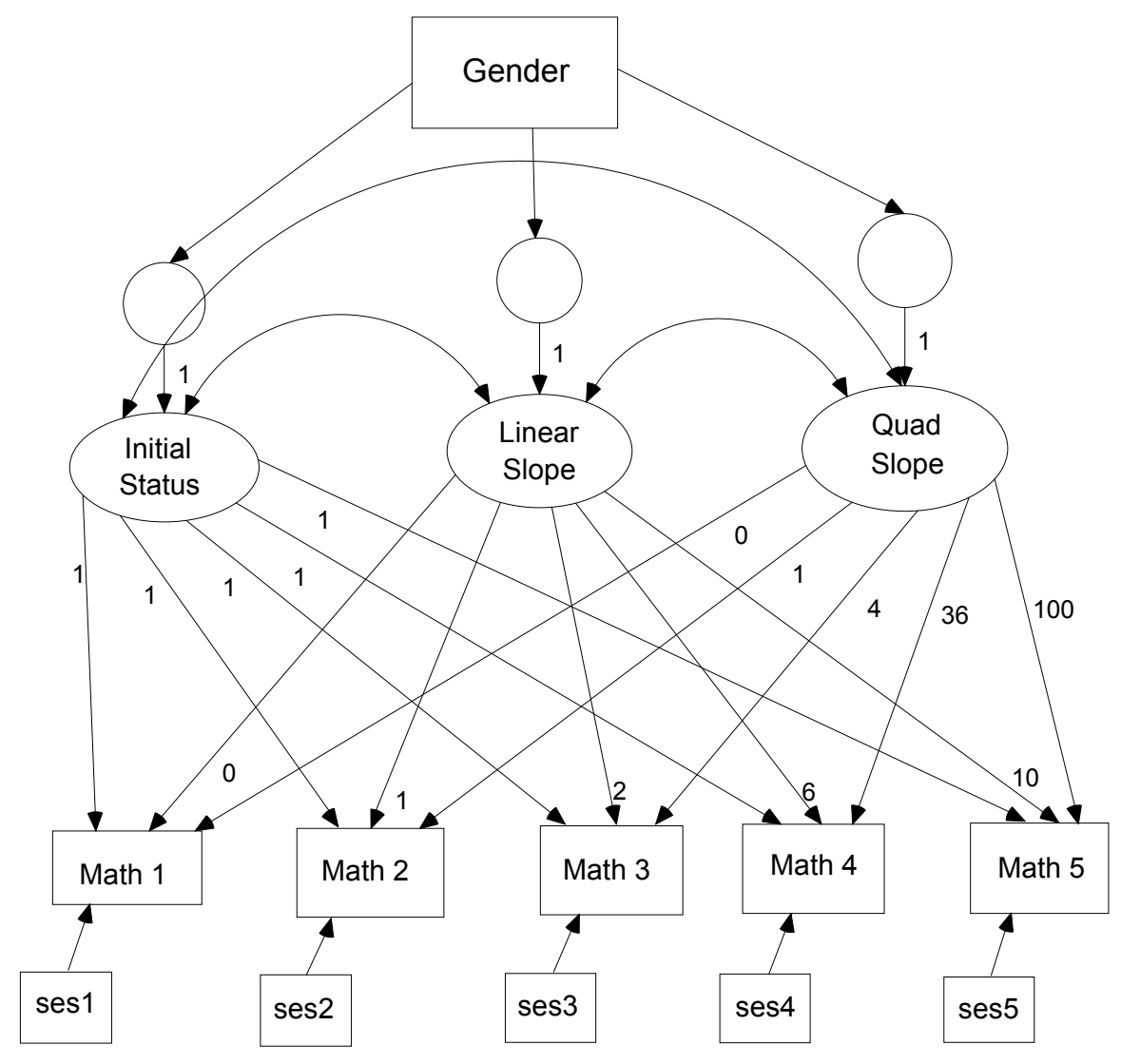

Figure 4. Conventional growth curve model of math achievement with time-invariant and time-varying predictors

Model 3 in Table 1 provides estimate for the growth curve model with time-invariant predictor gender, and time-varying predictor SES. A path diagram of this model is shown in Figure 4. Results for model 3 in Table 1 show that the addition of SES does not change the results dramatically compared with model 2, insofar as, holding SES constant, girls start with a significantly lower mean math IRT scores, have significantly slower linear growth rate, but significantly faster acceleration rate. In model 3, once taking into account of SES, the gender differences reduced as shown in Figure 5. The results for time-varying covariates in model 3 suggest that, holding gender constant, the effect of SES is weaker in the first three weaves than that in the last two weaves. 


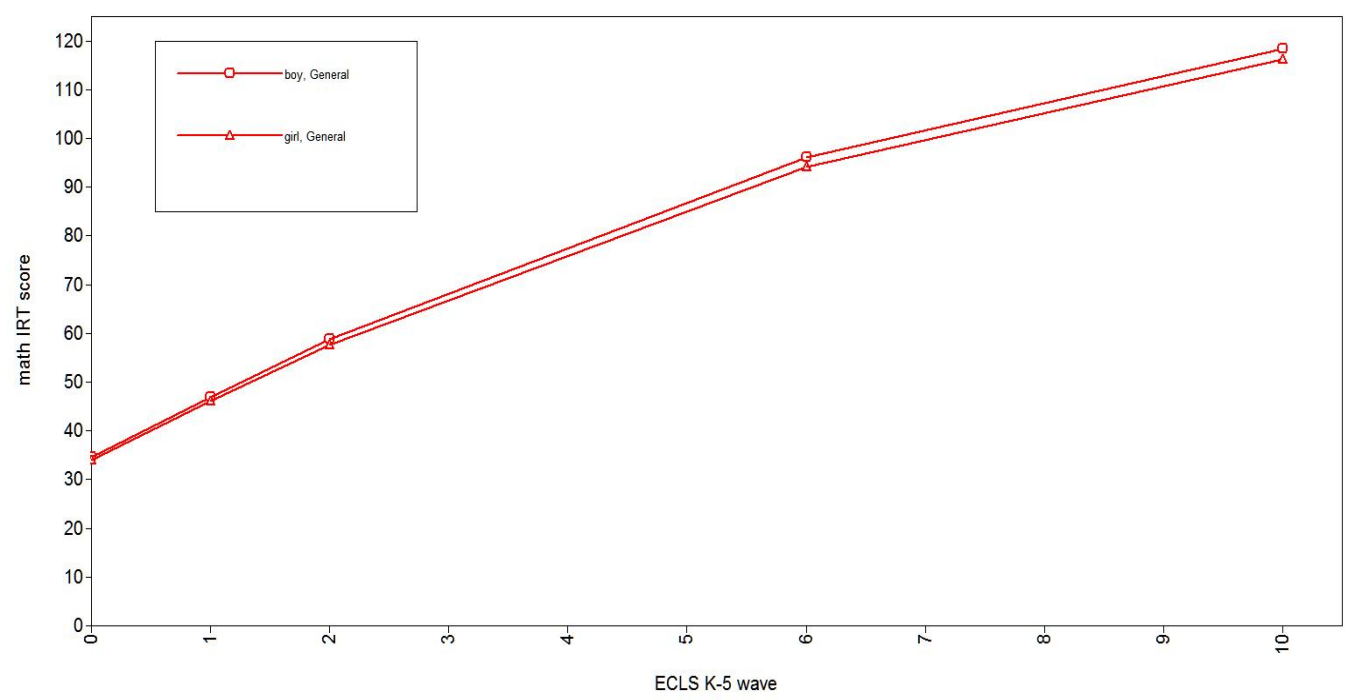

Figure 5. Estimated math growth trajectories for boys versus girls controlling for SES

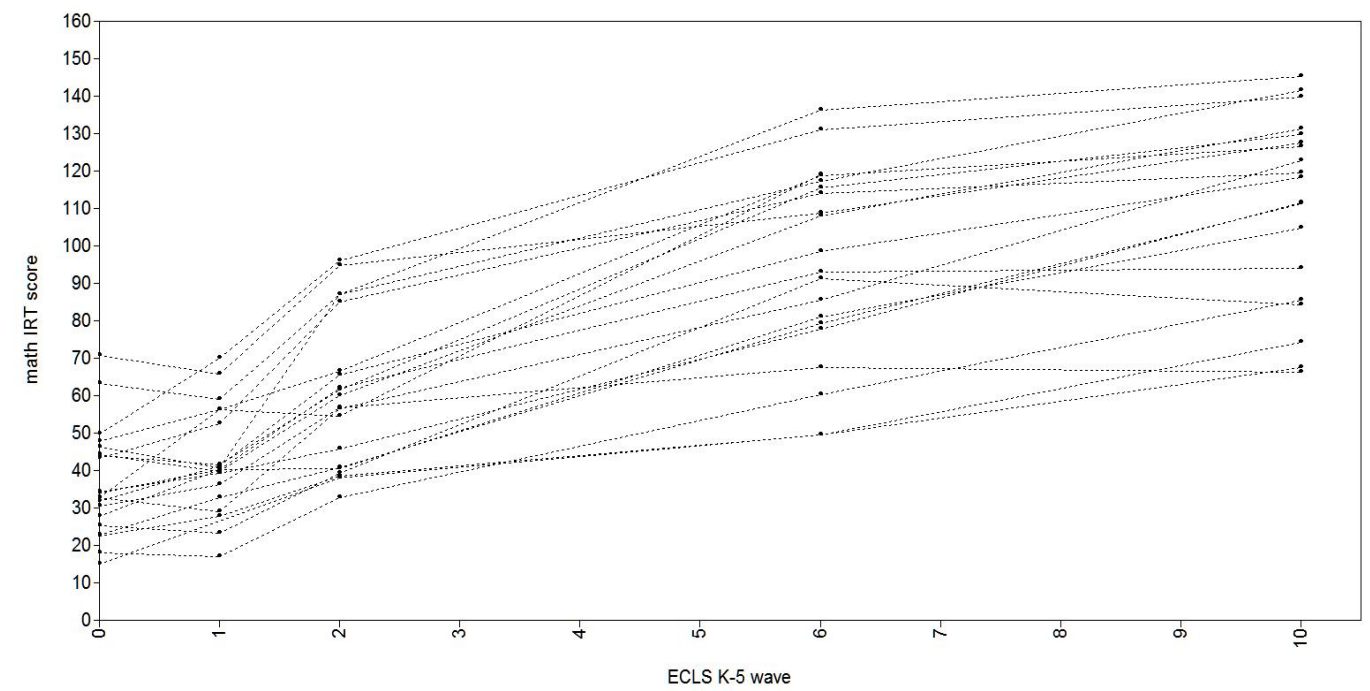

Figure 6. Empirical math growth trajectories for a random sample of 20 ECLS K-5 children

Figure 6 presents the empirical trajectories for 20 randomly chosen students on the math IRT scores over the selected five ECLS K-5 waves. In Figure 6, it shows that, over the selected time points, a few students start with a high math IRT scores and grow rapidly; majority of the students start with a medium math IRT scores and grow with a moderate speed; still other students start with relatively low math IRT scores and grow slower. The general picture in Figure 6 implies that a single population assumption in conventional growth curve model simplified the variety of students' math growth over time.

As noted earlier, conventional growth curve modeling assumes that the sample is drawn from a single population characterized by one set of average growth parameters. To test whether 


\section{Macrothink}

this assumption is plausible, the above three models were rerun in the framework of growth mixture modeling. When conducting growth mixture modeling, the optimal number of classes can be determined in a couple of ways: BIC, posterior probability, entropy, and substantive consideration (Connell \& Frye, 2006; Kaplan, 2002; Muthén 2003). Bayesian Information Criteria (BIC) is the most used model fit indices across models. In Mplus, BIC is calculated as the sum of -2 times the loglikelihood value of the model, plus the number of model parameters times the natural log of the sample size. Lower scores represent better fitting models. To begin with, a one-class, two-class, and three-class solution that did not contain any predictors were specified. The BIC values for these solutions are 123975.7, 107540.1, and 107003.1, respectively, suggesting that the three-class solution obtained the best fit. In addition to BIC, the posterior probabilities of classification based on three-class solution in table 2 shows reasonably good classification.

Table 2. Average posterior probabilities for three-class solution

\begin{tabular}{|l|l|l|l|}
\hline & Class 1 & Class 2 & Class 3 \\
\hline Class 1 & 0.938 & 0.062 & 0.000 \\
\hline Class 2 & 0.137 & 0.863 & 0.001 \\
\hline Class 3 & 0.000 & 0.000 & 1.000 \\
\hline
\end{tabular}

The quality of classification across models can also be examined by entropy. Entropy is a summary measure of the probability of membership in the most-likely class for each individual. There are no specific guidelines for interpreting entropy, but possible values ranges from 0 to 1.0 , and values closer to 1.0 represent better classification (Connell \& Frye, 2006). The entropy is 0.786 and 0.829 , respectively for 2 classes and 3 classes (not available for 1 class). Considering the justification and interpretability of latent trajectory classes, this paper classified the studied population into three classes: slower-math development class, moderate-math development class, faster-math development class. Mplus output shows that the proportion of these three classes is $35 \%, 57 \%$, and $8 \%$, respectively. Figure 7 presents the estimated math growth trajectories for these three classes. 


\section{Macrothink}

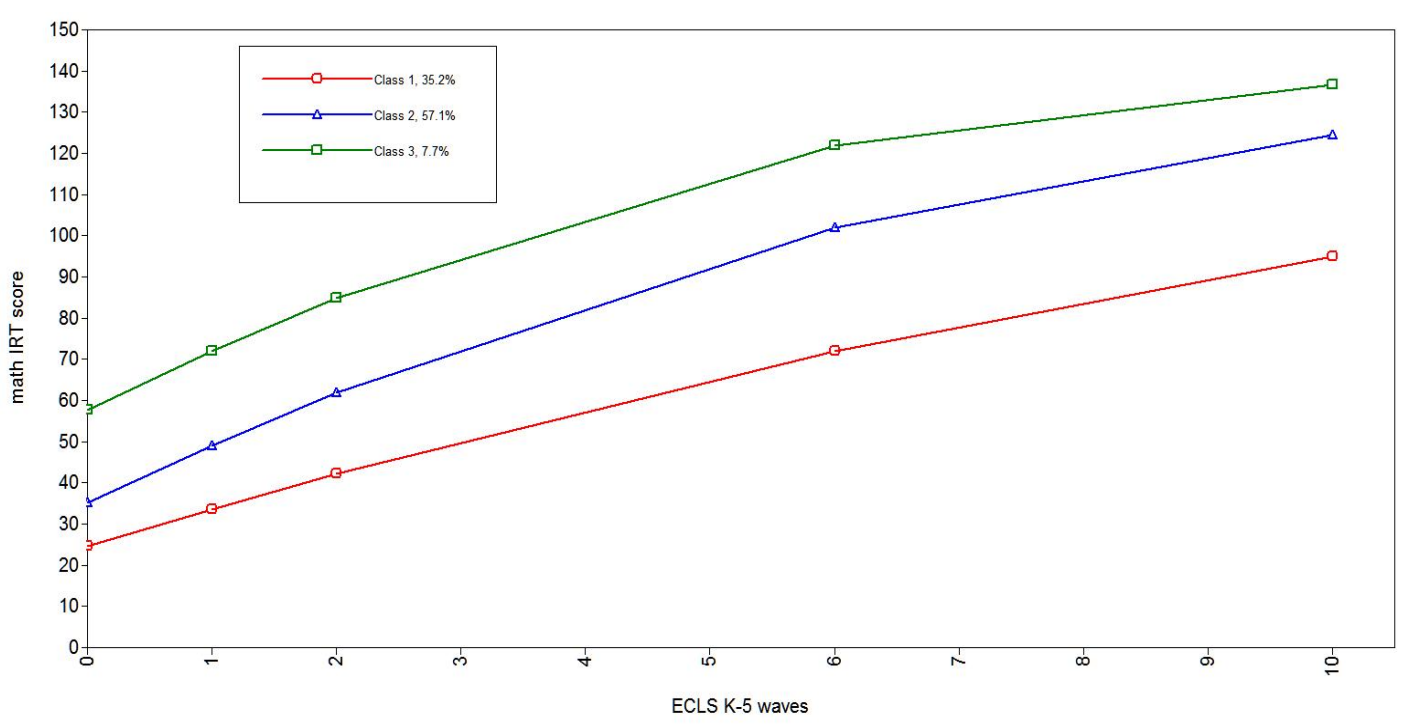

Figure 7. Estimated math growth trajectories by trajectory class

For each class, three models were then specified. The first model contains no predictors. The second model adds gender, and the third model contains both gender and SES as covariates. Figures 8 presents the estimated math growth trajectories for boys and girls based on growth mixture model. Figure 9 presents the estimated math growth trajectories for boys and girls in three classes when adding SES as time-varying covariate. Appendix 1 presents Mplus code used to conduct the analysis on model 3 (gender as time-invariant covariate and SES as time-varying covariate).

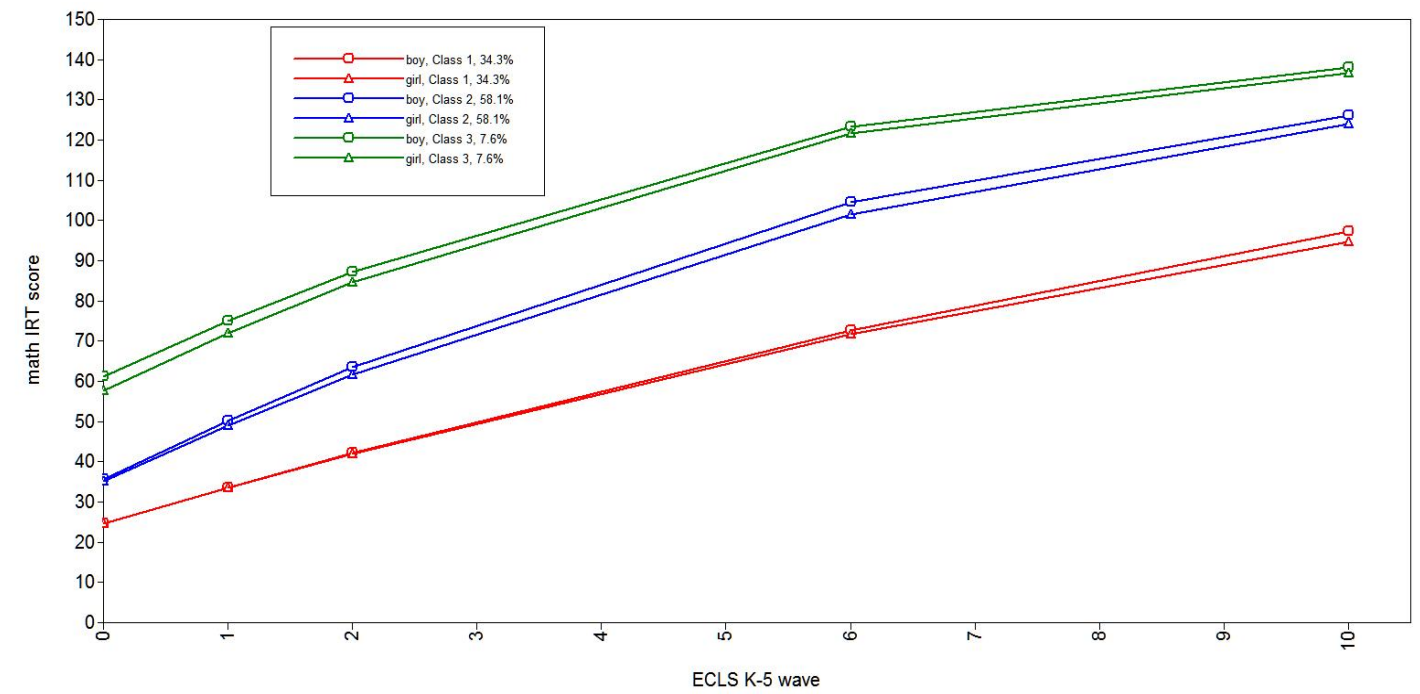

Figure 8. Estimated math growth trajectories for boys versus girls by trajectory class 


\section{MInstitute ${ }^{\text {Macrothink }}$}

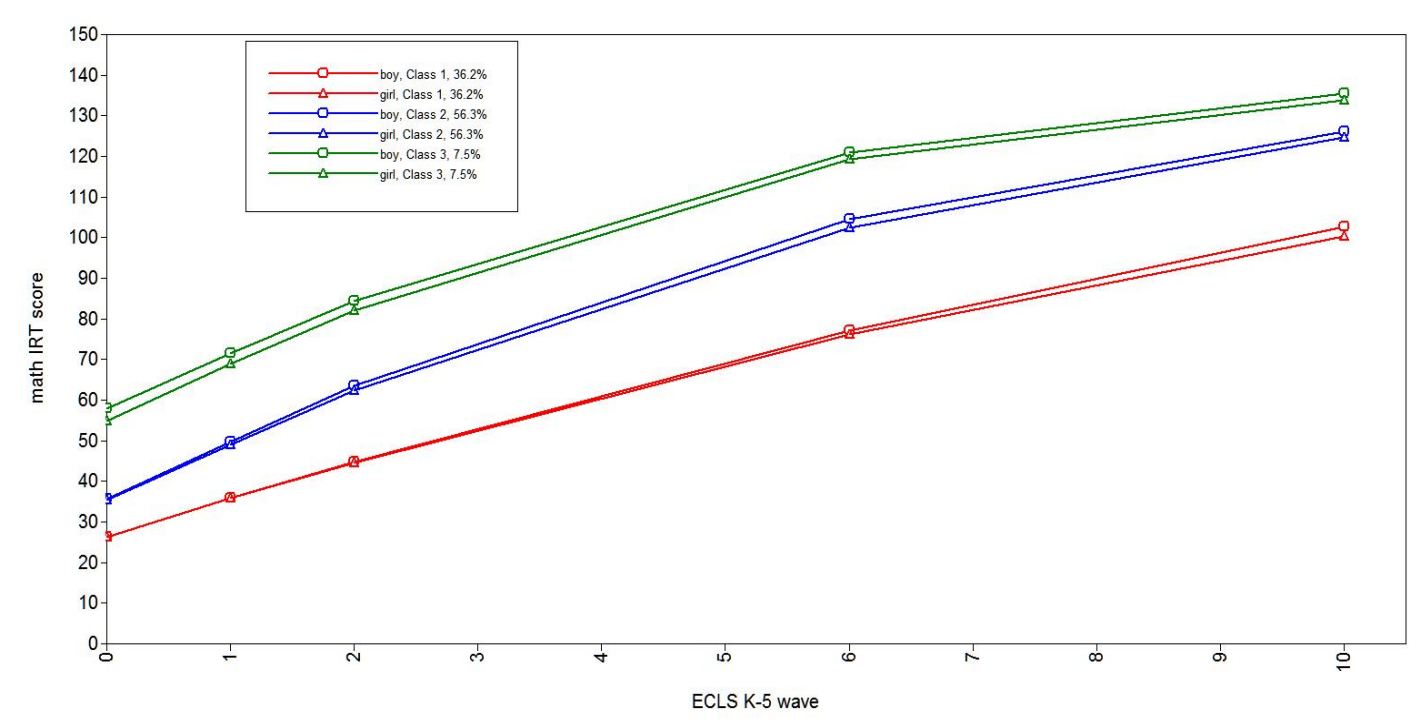

Figure 9. Estimated math growth trajectories for boys versus girls by trajectory class controlling for SES

Selected results for growth mixture models are shown in Table 3. An inspection of Table 3 shows that, in slower-math development class, girls are ahead of boys on mean IRT scores, grow faster but decelerate faster than boys. After controlling for SES, girls are behind of boys on mean start IRT scores, grow slower and decelerate faster. The differences between boys and girls on mean start IRT scores, linear and quadratic slopes are nonsignificant though. In moderate-math development class, girls are behind of boys on mean IRT start scores, grow slower but accelerate faster than boys. After controlling for SES, gender differences greatly reduced in moderate-math development class. The differences between boys and girls on mean start value are nonsignificant, but the differences are significant on the linear and quadratic slopes. In faster-math development class, girls are behind of boys on mean IRT start scores, grow slower but accelerate faster than boys. After controlling for SES, girls grow faster but also decelerate faster than boys. The differences between boys and girls are significant on the mean start value but nonsignificant on linear and quadratic slopes. An inspection of model 3 across three classes suggests that, after controlling for gender, the effect of SES is weaker in the first three waves than that in the last two waves in slower-math development class; in moderate-math development class, the effect of SES is approximately constant across the selected waves (except wave 2); in faster-math development class, the effect of SES is stronger in the first three waves than that in the last two waves.

\section{Discussion}

In the current study, the application of conventional growth curve modeling revealed that, there is significant difference on mean start math IRT scores between boys and girls in ECLS K-5 dataset, girls have significantly slower linear growth rate but faster acceleration rate in math achievement from kindergarten to Spring fifth. After controlling for SES, the gender differences reduced on the mean start math IRT scores, growth rate, and acceleration rate. 
Growth mixture modeling applied to ECLS K-5 children reliably identified three classes of children based on their math growth trajectories: a slower-math development class, a moderate-math development class, and a faster-math development class. Growth mixture modeling results indicate that gender differences are different depending on different math development classes. Specifically, gender differences in slower-math development class are statistically nonsignificant on the mean start math IRT scores, linear growth rate and acceleration rate. In normal-math development class, gender difference is statistically nonsignificant on the mean start math IRT scores, but gender differences are statistically significant on linear growth rate and acceleration rate. In faster-math development class, gender difference is statistically significant on the mean start math IRT scores, but gender differences are statistically nonsignificant in terms of linear growth rate and acceleration rate. When holding SES constant, growth mixture modeling results show that gender differences on the mean start IRT scores, linear growth rate, and quadratic growth rate reduced in all subpopulations.

Table 3. Selected results for three growth mixture models

\begin{tabular}{|c|c|c|c|c|c|c|c|c|c|}
\hline \multirow[b]{2}{*}{ Coeff } & \multicolumn{3}{|c|}{ Slow Math Development } & \multicolumn{3}{|c|}{ Normal Math Development } & \multicolumn{3}{|c|}{ Fast Math Development } \\
\hline & Model1 & Model2 & Model3 & Model1 & Model2 & Model3 & Model1 & Model2 & Model3 \\
\hline I & 24.703 & 24.533 & 25.928 & 35.186 & 35.706 & 34.880 & 57.697 & 61.278 & 56.788 \\
\hline $\mathrm{S}$ & 9.142 & 9.170 & 9.675 & 14.409 & 15.070 & 15.174 & 14.929 & 14.349 & 14.881 \\
\hline Q & -0.213 & -0.190 & -0.209 & -0.549 & -0.603 & -0.610 & -0.702 & -0.668 & -0.705 \\
\hline I on gender & & 0.076 & -0.054 & & -1.072 & -0.448 & & -6.934 & -5.758 \\
\hline $\mathrm{S}$ on gender & & 0.099 & -0.076 & & -1.448 & -1.137 & & -0.871 & 0.641 \\
\hline Q on gender & & -0.042 & -0.038 & & 0.115 & 0.089 & & 0.043 & $-\mathbf{0 . 0 3 8}$ \\
\hline Math1 on SES1 & & & 2.748 & & & 4.572 & & & 7.122 \\
\hline Math2 on SES2 & & & 4.953 & & & 2.244 & & & 4.886 \\
\hline Math3 on SES3 & & & 2.643 & & & 5.770 & & & 5.832 \\
\hline Math4 on SES4 & & & 7.390 & & & 6.727 & & & 3.237 \\
\hline Math5 on SES5 & & & 8.760 & & & 5.685 & & & 4.007 \\
\hline
\end{tabular}

Note. Number in bold indicate nonsignificant; I: intercept; S: slope; Q: quadratic; SES = socio-economic status; boys $=0$, girls $=1$.

Growth mixture modeling result also show that after controlling for gender, the effects of SES on math development are different in different subpopulations. SES is probably the most 
widely used contextual variable in educational research. Consistent with the effect of SES on math achievement in the conventional growth model, the addition of SES in the growth mixture model reduced gender differences in all the subpopulations. Clearly, more research is needed to determine the effect of SES on individual academic differences in early childhood.

With regard to performance by gender on mathematical related assessments among K-12 students, the literature has mixture findings. Some studies found a higher achievement for boys (e.g., Rathbun \&West, 2004; Fryer \& Levitt, 2010; Penner \& Paret, 2007), for girls (e.g.,Vermeer, Boekaerts, Seegers, 2000), and no difference between boys and girls (e.g., e.g, Campbell, Hombo, \& Mazzeo, 2000; Cheema \& Galluzzo, 2013; Hyde, Fennema, \& Lamon, 1990; Ingels \& Dalton, 2008; Stoet \& Geary, 2013). The current analysis only considers one of the important factors, social economic status, that affect children's academic achievement, With the addition of some other covariates, such as time spent on the homework, parent education, and school type, etc. the gender differences on math growth curve would not necessarily hold. Therefore, the implicit gender-math stereotypes should not influence women's interest and performance in math domain.

By focusing the analysis to students who stayed in the same school from kindergarten to the fifth grade, there are a couple of limitations in this study. As we know low SES students are more likely to move, it would be interesting to see whether similar results could be hold for students who changed schools in the elementary years. This study sampled 2818 students from the whole dataset. Future study will consider incorporating sampling weight in the model to get more plausible estimation.

\section{References}

Bradley, R. H., \& Corwyn, R. F. (2002). Socioeconomic status and child development. Annual Review of Psychology, 57, 371-399. http://dx.doi.org/10.1146/annurev.psyc h.53.100901.135233

Campbell, J. R., Hombo, C. M., \& Mazzeo, J. (2000). NAEP Trends in Academic Progress: Three Decades of Student Performance. Washington, DC: U.S. Department of Education, Office of Educational Research and Improvement. National Center for Education Statistics.

Cheema, J. R., \& Galluzzo, G. (2013). Analyzing the gender gap in math achievement: Evidence from a large-scale US sample. Research in Education, 90, 98-112. http://dx.doi.org/10.7227/RIE.90.1.7

Clogg, C. C. (1995). Latent class models. In G. Arminger, C. C. Clogg, \& M. E. Sobel (Eds.), Handbook of statistical modeling in the social and behavioral sciences (pp. 81-110). San Francisco: Jossey-Bass. http://dx.doi.org/10.1007/978-1-4899-1292-3_6

Connell, A. M., \& Frye, A. A. (2006). Growth mixture modeling in developmental psychology: Overview and demonstration of heterogeneity in developmental trajectories of adolescent antisocial behavior. Infant and Child Development, 15, 609-621. http://dx.doi.org/10.1002/icd.481

Dawson, B. A., \& Williams, S. A. (2008). The impact of language status as an acculturative 
stressor on internalizing and externalizing behaviors among Latino children: A longitudinal analysis from school entry through third grade. Youth Adolescence, 37, 399-411. http://dx.doi.org/10.1007/s10964-007-9233-z

Duncan, G. J., \& Magnuson, K. A. (2005). Can family socioeconomic resources account for racial and ethnic test scores gaps? The Future of Children, 15, 35-54. Retrieved from http://nces.ed.gov/pubsearch/pubsinfo.asp?pubid=2006032

Fryer, R. G., \& Levitt, S. D. (2010). An empirical analysis of the gender gap in mathematics. American Economic Journal: Applied Economics, American Economic Association, 2(2), 210-240. http://dx.doi.org/10.1257/app.2.2.210

Han, W. (2008). The academic trajectories of children of immigrants and their school environments. Developmental Psychology, 44, 1572-1590. http://dx.doi.org/10.1037/a001 3886

Hong, G., \& Raudenbush, S. W. (2005). Effects of kindergarten retention policy on children's cognitive in reading and mathematics. Educational Evaluation and Policy Analysis, 27, 205-224. http://dx.doi.org/10.3102/01623737027003205

Hyde, J. S., Fennema, E., \& Lamon, S. (1990). Gender differences in mathematics performance: A meta-analysis. Psychological Bulletin, 107, 139-155. http://dx.doi.org/10. 1037/0033-2909.107.2.139

Ingels, S. J., \& Dalton, B. W. (2008). Trends Among High School Seniors, 1972-2004 (NCES 2008-320). Washington, DC: National Center for Education Statistics, Institute for Education Sciences, U.S. Department of Education.

Jung, T., \& Wickrama, K. A. S. (2008). An introduction to latent class growth analysis and growth mixture modeling. Social and Personality Psychology Compass, 2, 302-317. http://dx.doi.org/10.1111/j.1751-9004.2007.00054.x

Kaplan, D. (2002). Methodological advances in the analysis of individual growth with relevance to education policy. Peabody Journal of Education, 77, 189-215. http://dx.doi.org/10.1207/S15327930PJE7704_9

Kaplan, D. (2005). Finite Mixture Dynamic Regression Modeling of Panel Data with Implications for Dynamic Response Analysis, Journal of Educational and Behavioral Statistics, 30, 169-187. http://dx.doi.org/10.3102/10769986030002169

Lindberg, S. M., Hyde, J. S., Petersen, J. L., \& Linn, M. C. (2010). New trends in gender and mathematics performance: A meta-analysis. Psychological Bulletin, 136(6), 1123-1135. http://dx.doi.org/10.1037/a0021276

McCoach, D. B., O’Connell, A. A., \& Levitt, H. (2006). The effects of ability grouping in kindergarten reading using the ECLS-K. Journal of Educational Research, 99, 339-345. http://dx.doi.org/10.3200/JOER.99.6.339-346

Muthén, B. O. (2002). Beyond SEM: General latent variable modeling. Behaviormetrika, 29, 
81-117. http://dx.doi.org/10.2333/bhmk.29.81

Muthén, B. O. (2003). Statistical and substantive checking in growth mixture modeling: Comment on Bauer and Curran. Psychological Methods, 8, 369-377. http://dx.doi.org/10.1037/1082-989X.8.3.369

Muthén, L. K., \& Muthén, B. O. (2001). Mplus: Statistical analysis with latent variables. Los Angeles: Muthén \& Muthén.

Nesselroade, J. R. (1991). Interindividual differences in intraindividual change. In L. A. Collins \& J. L. Horn (Eds.), Best Methods for the Analysis of Change (pp. 92-106). Washington, DC: American Psychological Association. http://dx.doi.org/10.1037/10099-006

Penner, A. M., \& Parent, M. (2008). Gender differences in mathematic achievement: Exploring the early grades and the extremes. Social Science Research, 37, 239-253. http://dx.doi.org/10.1016/j.ssresearch.2007.06.012

Rathbun, A., \& West, J. (2004) From Kindergarten through Third Grade: Children's Beginning School Experiences (NCES 2004-007). U.S. Department of Education, National Center for Education Statistics. Washington, DC: U.S. Government Printing Office.

Raudenbush, S. W. (2001). Toward a coherent framework for comparing trajectories of individual change. In In L. M. Collins \& S. A. Sayer (Eds.), New methods for the analysis of change: Decade of behavior (pp. 35-64). Washington, DC, US: American Psychological Association. http://dx.doi.org/10.1037/10409-002

Singer, J. D., \& Willet, J. B. (2003). Applied longitudinal data analysis: Modeling change and event occurrence. New York: Oxford University Press, Inc. http://dx.doi.org/10.1093/acprof:oso/9780195152968.001.0001

Sirin, S. R. (2005). Socioeconomic status and academic achievement: A meta-analytic review of research. Review of Educational Research, 75, 417-453. http://dx.doi.org/10.3102/0034654 3075003417

Stoet, G., \& Geary, D. C. (2013). Sex differences in mathematics and reading achievement are inversely related: Within- and across-nation assessment of 10 Years of PISA Data. PLoS ONE, 8(3), e57988. http://dx.doi.org/10.1371/journal.pone.0057988

Thompson, T., \& Dinnel, D. L. (2007). Poor performance in Mathematics: Is there a basis for a self-worth explanation for women? Educational Psychology, 27, 377-399. http://dx.doi.org/10.1080/01443410601104197

Tourangeau, K., Nord, C., Lê, T., Pollack, J. M., \& Atkins-Burnett, S. (2006). Early Childhood Longitudinal Study, Kindergarten Class of 1998-99 (ECLS-K), Combined User's Manual for the ECLS-K Eighth-Grade Data Files and Electronic Codebooks (NCES 2006-032). Institute of Education Sciences, U.S. Department of Education. Washington, DC: National Center for Education Statistics.

U.S. Department of Education, National Center for Education Statistics. (2000). Early 


\section{Macrothink}

Childhood Longitudinal Study, Kindergarten Class of 1998-99. Washington, DC.

Vermeer, H. J., Noekaerts, M., \& Seegers, G. (2000). Motivational and gender differences: Sixth-grade students' mathematical problem-solving behavior. Journal of Educational Psychology, 92(2), 308-315. http://dx.doi.org/10.1037/0022-0663.92.2.308

Xue, Y., \& Meisels, S. J. (2004). Early literacy instruction and learning in kindergarten: Evidence from the Early Childhood Longitudinal Study: Kindergarten class of 1998-1999. American Educational Research Journal, 41, 191-229. http://dx.doi.org/10.3102/00028312041001191

\section{Appendix}

Appendix 1. Mplus Syntax for Growth Mixture Model 3

Title: Growth Mixture Modeling with time-invariant covariate gender and time-variant covariate SES

Data: File is GMM_4.dat;

Format $6 \mathrm{f} 10.2,4 \mathrm{f} 10.2, \mathrm{f} 10.0$;

Variable: Names are C1R3MSCL C2R3MSCL C3R3MSCL C4R3MSCL C5R3MSCL C6R3MSCL WKSESL W1SESL W3SESL W5SESL BOY;

Usevariables are C2R3MSCL C3R3MSCL C4R3MSCL C5R3MSCL C6R3MSCL WKSESL W1SESL W3SESL W5SESL BOY;

$$
\begin{aligned}
& \text { missing }=; \\
& \text { classes }=\mathrm{c}(3)
\end{aligned}
$$

Analysis:TYPE IS MIXTURE;

$$
\begin{aligned}
& \text { Estimator = ML; } \\
& \text { Starts = } 1000 \text { 50; } \\
& \text { STITERATIONS = 50; }
\end{aligned}
$$

Model: \%overall\%

i by C2R3MSCL-C6R3MSCL@1;

s by C2R3MSCL@0 C3R3MSCL@1 C4R3MSCL@2 C5R3MSCL@6 C6R3MSCL@10;

q by C2R3MSCL@0 C3R3MSCL@1 C4R3MSCL@4 C5R3MSCL@36 C6R3MSCL@100; 
[C2R3MSCL-C6R3MSCL@0 is q];

iwith s@0;

i with q@0;

s with q@0;

i s q on BOY;

C2R3MSCL on WKSESL;

C3R3MSCL on W1SESL;

C4R3MSCL on W1SESL;

C5R3MSCL on W3SESL;

C6R3MSCL on W5SESL;

\section{$\% \mathrm{c} \# 1 \%$}

[i*17.2 s*6.2 q*-0.2];

i s q on BOY;

C2R3MSCL on WKSESL;

C3R3MSCL on W1SESL;

C4R3MSCL on W1SESL;

C5R3MSCL on W3SESL;

C6R3MSCL on W5SESL;

C6R3MSCL@0;

\section{$\% \mathrm{c} \# 2 \%$}

[i*33.4 s*13.1 q*-0.4];

i s q on BOY;

C2R3MSCL on WKSESL;

C3R3MSCL on W1SESL;

C4R3MSCL on W1SESL;

C5R3MSCL on W3SESL;

C6R3MSCL on W5SESL;

q@0;

C6R3MSCL@0;

$$
\begin{aligned}
& \% \mathrm{c} \# 3 \% \\
& \quad\left[\mathrm{i} * 50.4 \mathrm{~s}^{*} 20.1 \mathrm{q}^{*}-0.6\right] \\
& \text { i s q on BOY; }
\end{aligned}
$$


C2R3MSCL on WKSESL;

C3R3MSCL on W1SESL;

C4R3MSCL on W1SESL;

C5R3MSCL on W3SESL;

C6R3MSCL on W5SESL;

q@0;

C6R3MSCL@0;

Plot: Type $=$ plot3;

Series $=\mathrm{C} 2 \mathrm{R} 3 \mathrm{MSCL}(0) \quad \mathrm{C} 3 \mathrm{R} 3 \mathrm{MSCL}(1) \quad \mathrm{C} 4 \mathrm{R} 3 \mathrm{MSCL}(2) \quad \mathrm{C} 5 \mathrm{R} 3 \mathrm{MSCL}(6)$ C6R3MSCL(10);

output:

tech1 tech4 tech8;

\section{Copyright Disclaimer}

Copyright for this article is retained by the author(s), with first publication rights granted to the journal.

This is an open-access article distributed under the terms and conditions of the Creative Commons Attribution license (http://creativecommons.org/licenses/by/3.0/). 